\title{
Artery of Adamkiewicz and the clinical repercussion of its lesion in thoracoabdominal surgeries: a systematic review
}

Idna Lara Goes de Sena 1, Maria Regina Cardoso Linhares Oliveira Lima 1, Lia de Oliveira Jereissati 1, Rafaella Iughetti da Costa 1, Victor Oliveira Araújo 1, Isadora Mônica Ponte de Oliveira 1, Lara Maria de Oliveira Paiva Freitas 1, Maria Victoria Rocha Fontenele Maia 1, Aline Moreira Lócio 1, Júlio César Claudino dos Santos 1, 2, 3, *.

${ }^{1}$ Faculdade de Medicina, Centro Universitário Christus, UNICHRISTUS, Fortaleza, Ceará, CE, Brazil.

2 Universidade Federal de São Paulo, São Paulo, SP, Brazil.

${ }^{3}$ Laboratório de Neurociências, Departamento de Neurologia e Neurocirurgia, Universidade Federal de São Paulo, São Paulo, SP, Brasil.

*Corresponding author: Júlio César Claudino dos Santos. Departamento de Neurologia e Neurocirurgia. Universidade Federal de São Paulo. Rua Sena Madureira, 1500 - Vila Clementino. Zip Code: 04021-001 - São Paulo, SP, Brazil. Phone: +55 (19) 9 8450-6660. E-mail: cesar.claudino@unifesp.br.

Received on: Mon X, 2021. Accepted on: Oct 3, 2021. Available online: Oct 3, 2021.

\section{Abstract}

The knowledge of the spinal cord irrigation is important for the therapeutic planning of aortic pathologies; however, its vasculature is complex due to the caliber of its arteries that pass through a three-dimensional network with great anatomical variability. Its clinical importance is evidenced during the preoperative procedure of thoracic and thoracoabdominal aortic surgeries, because its identification is essential for the prevention of spinal cord injuries. This study consists of a literature review, in which searches were conducted in the databases - Bireme, Science Direct, Pubmed and Lilacs. Articles published between 1999 and 2020, written in English, Portuguese or Spanish, were selected. The search was conducted using the descriptors Anatomy, Spinal Cord Irrigation and Spinal Cord Ischemia. The Adamkiewicz artery is the main artery responsible for the arterial supply to the lower part of the spinal cord. Thus, paraplegia is a complication of this type of surgical approach resulting from ischemic suffering of the spinal cord during the process. Therefore, further study on these factors should be encouraged, because the preservation of this vessel is relevant given the search for protection of the spinal cord and the maintenance of its functions in this type of procedure.

Keywords: Adamkievcz Artery; Neurology; Surgery.

\section{Introduction}

One of the applications in the field of medical neurology are neurovascular syndromes, which can have different etiologies such as atherosclerotic, arteriovenous malformations, aortic aneurysm repair, 
and embolism. From this perspective, spinal cord infarction is less common compared to the occurrence of a stroke; however, its consequences are potentially more disabling overall. The most common spinal cord neurovascular syndrome is related to the anterior spinal artery. Associated with this, risk factors have been shown to be pertinent, such as advanced age, hypertension, and diabetes mellitus [12].

The spinal cord is one of the components of the central nervous system (CNS) and is held within the spinal canal. It begins below the foramen magnum or below the pyramidal decussation, which is located at the end of the medulla oblongata. Its end, the medullary cone, is often located at the level of the second lumbar vertebra (L2). It contains two intumescences along its trajectory, where the deposition of neurons is increased. The first is the cervical intumescence related to the brachial plexus; the second, lumbar, covers the lumbosacral plexus [3-4].

Knowledge about the irrigation of the spinal cord is important for therapeutic planning of aortic diseases, but its vasculature is complex and difficult to study due to the small caliber of its arteries, which travel through an intricate three-dimensional network that has great anatomical variability [5].
This irrigation was first studied by the Polish pathologist Albert W. Adamkiewicz in 1882. For this reason, the arteria radicularis magna, the most calibrous of the radicular arteries and responsible for the irrigation of the lower two thirds of the spinal cord, bears his name as an eponym and is known as the Adamkiewicz Artery [6-8].

The spinal cord vasculature consists of three main arteries. The anterior spinal artery irrigates the anterior two-thirds, supplying the gray matter and the anterolateral regions of the medullary white matter. This vessel originates in the intracranial portion of the vertebral arteries. Two posterior vertebral arteries also contribute to the process, supplying the posterior third of the spinal cord and, consequently, the fasciculus graciosus and cuneate, which are contained in the posterior funiculus of the medullary white matter. They are branches of the posterior inferior cerebellar artery (PICA), which is also a branch of the vertebral artery [4, 9-10].

Adamkiewicz's artery is also known as radicularis magna or large anterior radiculomedullary artery. Its anatomical composition begins at the level of the descending aorta, from which the lumbar or intercostal arteries emerge and are divided into posterior and anterior. The dorsal somatic, muscular and radiculomedullary branches originate in the posterior 
segment. This last one is divided into two portions: the main anterior and the minor posterior. The Adamkiewicz artery is the largest among the anterior radiculomedullary arteries. In addition, more than one Adamkiewicz artery can be found within the same individual [4, 10-11].

The arteria radicularis magna has continuity within the intervertebral foramen, following the ventral root of the spinal nerve and projecting into the anterior portion of the spinal cord. In this region, it is possible to observe its association with the anterior spinal artery (ASA), forming a characteristic hairpin-shaped arch. In most individuals, only one Adamkiewicz artery is present and it is located to the left of the aorta at its thoracic and lumbar levels. However, this anatomy can have variations such as being located on the right side of the aorta or originating at a level outside of T8 to L1 [12-13].

Its clinical importance is highlighted during preoperative procedures of thoracic or thoracoabdominal aortic surgeries because its identification and localization by neuroimaging techniques is essential to prevent spinal cord injuries, since the interruption of its pathway presents a marked risk factor for symptomatic spinal cord ischemia. [14-15].
Thus, pre-operation identification of the great radicular artery, as well as knowledge of its anatomy and morphological variability are necessary for superior surgical planning. It is essential that this relationship occurs in order to decrease complications during surgery or after thoracoabdominal and retroperitoneal surgical procedures that may cause neurological damage to patients. Furthermore, it is reasonable to give preference to neuroimaging examinations that cover pillars such as accurate identification of the Adamkiewicz artery and its collateral circulation, rapid processing, and easy accessibility [10].

\section{Methodology}

This article presents a biographical review study with a descriptive basis accomplished from the analysis of scientific articles published during 1999-2020 on the data of PubMed, Science Direct, Lilacs and Bireme, using as keywords: neuroanatomy, spinal cord, spinal cord infarct and neurology. However, it was realized that the terms Adamkiewicz artery and major anterior radicular artery (Adamkiewicz) aren't recognized as descriptors.

The terminologies utilized are according to the DeCS (Health Science Descriptors). The article search had been done within the period of august to 
october of 2020, through the periodicals on the internet. Posteriorly, the materials were selected using the following inclusion standards: theme approach, publication date situated in the years between 1999 and 2020; article available in full or summary version and study in humans.The representation of the articles found in number of included and excluded, as well their applicated distribution are shown in Figure 1.

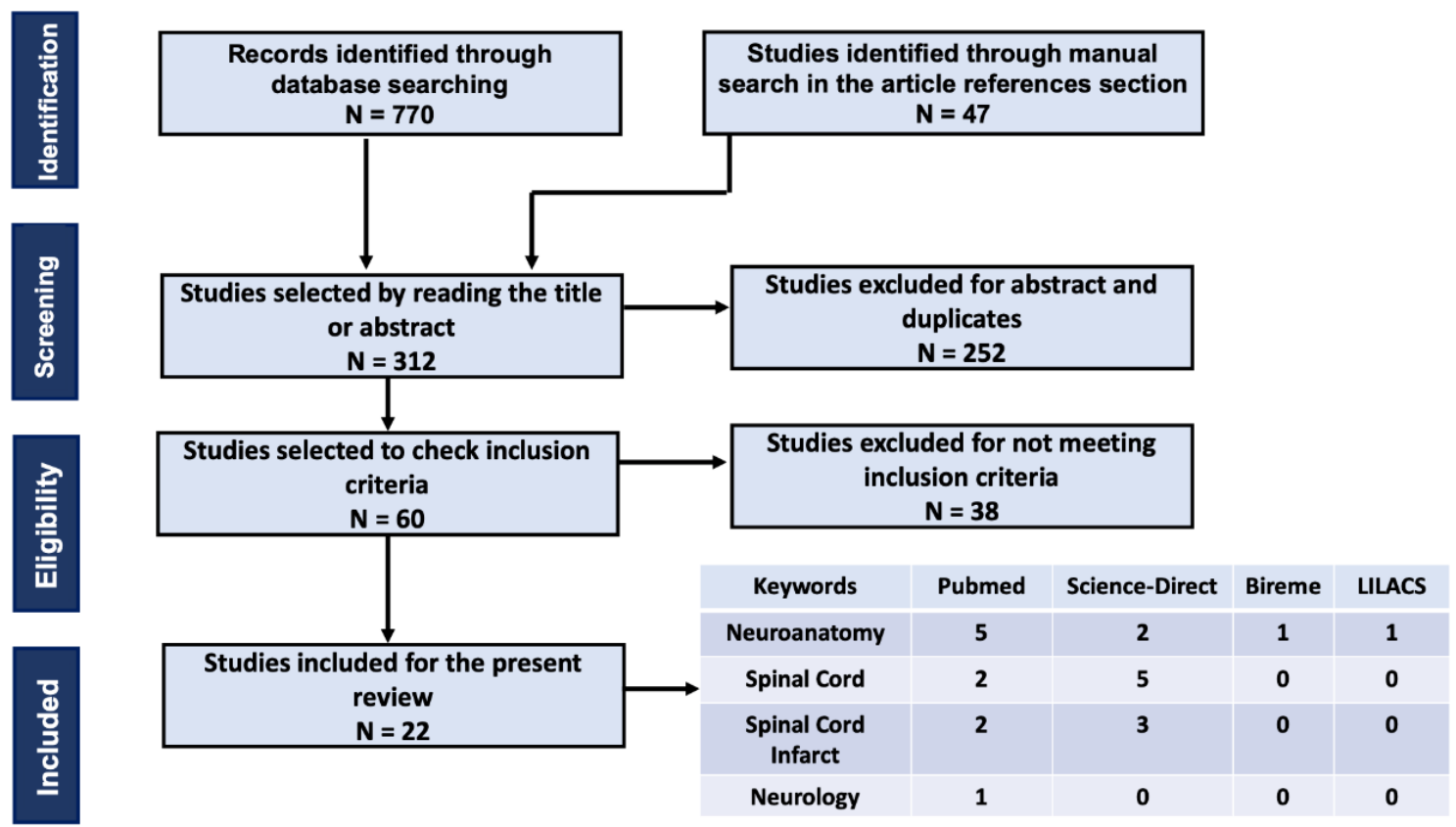

Figure 1. Flow diagram for inclusion/exclusion and data processing.

\section{Results (Review)}

The bibliographical review study showed the anatomic relations and clinical correlations of the arteria radicularis magna. Table 1 shows the overview of the general approaches of the Adamkiewicz artery case studies.

Undoubtedly, knowledge of spinal cord irrigation is important in the therapeutic planning of aortic diseases, however, its vasculature is complex and difficult to study due to the small caliber of its arteries that run in an intricate three-dimensional network with great anatomical variability. Therefore, the absence of a gold standard imaging exam also makes it difficult to compare existing imaging methods. According to Adamkiewicz's partial flow theory, the 
flow in the anterior spinal artery departs from the radicular arteries when arriving in the medulla in two streams, one cranial and the other caudal, and, thus, the pressure change, or occlusion of the collateral network pathway, can reverse flow in the anterior spinal artery [1].

As stated in Amato et al. [5], the intercostal and lumbar arteries that supply the spinal cord originate from the aorta, as do the subclavian and hypogastric branches. The article affirms that the lumbar and intercostal arteries divide three times before reaching the spinal cord. Its first branch is the spinal, which divides into the anterior and posterior radicular arteries, and further on it bifurcates into the dorsal and vertebral branches. The last bifurcation of the spinal branch is constant for the anterior and posterior supply of the spinal canal, nerve roots and dura mater, only at some levels the anterior and posterior radicular arteries cross the dura mater and reach the medulla [1].

Only a few (2-14, mean 6) of these segmental branches persist into adulthood. Also, the anterior spinal artery (ASA), crucial for medullary vascularization and anterior and lateral funiculi, is basically an anastomotic channel between the ascending and descending approximately branches of the adjacent anterior radicular arteries. Usually one of the anterior radicular arteries is dominant over the others in caliber and is called the great anterior radicular artery or the Adamkiewicz artery. The posterior radicular artery has a similar pattern, but gives rise to two longitudinal anastomotic channels: the posterolateral spinal arteries. Arteries that supply the spinal cord are divided into a central system, fed by the sulcal arteries, and another peripheral system, the pial plexus, which gives rise to perforating branches [1].

According to Moore et al. [16], the anterior radicular artery (of Adamkiewicz), enhances circulation to two-thirds of the spinal cord, including lumbosacral tumescence. It is much larger than the other segmental medullary arteries and usually originates via a spinal branch from an inferior intercostal artery or superior lumbar artery, entering the vertebral canal through the foramen IV at the inferior thoracic or superior lumbar level. Therefore, some clinical correlations were found as the deficiency in vascularization (ischemia) of the spinal cord affects its function and can cause muscle weakness and paralysis. The spinal cord can also suffer circulatory impairment if the segmental medullary arteries, particularly the anterior radicular artery (of Adamkiewicz), are narrowed by obstructive arterial disease. As stated in the study from Koakutsu et al. [31], the 
Adamkiewicz artery was shown to often bifurcate from a lumbar spine or an intercostal artery at the thoracic junction, where spinal injury most commonly occurs. This indicates the need for careful attention to lumbar artery injury in the management of patients with lumbar spine injury. Once a lesion in the lumbar artery is found, transcatheter arterial embolization may be the treatment of choice, with careful attention to the Adamkiewicz artery [20].

Evidently, the knowledge about anatomical locations of the Adamkiewicz artery in spine surgery is essential, as it allows you to reliably determine the topography of the Adamkiewicz artery. If the planned surgical approach is located at the same level, a contralateral approach or selective surgical techniques without vessel ligation could prevent possible damage to the Adamkiewicz artery, if pathology does not dictate the side and extent of the surgical approach. As stated in Charles et al. [17], the Adamkiewicz artery was always located between $\mathrm{T} 8$ and $\mathrm{L} 3$, at $\mathrm{T} 9$ or $\mathrm{T} 10$ in $50 \%$, and came from the left side in $75 \%$ of cases [5]. Similar results were achieved in other studies.

In a study using MDCT angiography of the spinal vasculature and the artery of Adamkiewicz by Boll et al. [18], the results showed that in
$63 \%$ of the patients the AKA originated from the left side of the body, and in $74 \%$ it originated from the level of the 10th-12th thoracic vertebra. Duplications were found in $5 \%$ of patients [4]. Additionally, a study by Melissiano et al. [19], with multidetector Computed Tomography Angiography analysed with the Open-Source Software OsiriX found out that the AKA originated from the left intercostal artery in $384(83.3 \%)$ cases [17].

Also, the neuroradiology research by Bley et al. [20], has shown that the Adamkiewicz artery origins were on the left side of the body in $65 \%$ of patients and on the right side in $35 \%$. The level of origin varies from the T6 neural foramen to the L1 neural foramen [3].

Moreover, the Koshino et al. [21] research showed that approximately $70 \%$ of the Adamkiewicz arteries originated from the intercostal and/or lumbar arteries on the left side, often at the T8-L1 vertebral level. Indisputably, during operations for thoracoabdominal aortic aneurysms, detailed anatomical knowledge of the Adamkiewicz artery and its correlation with the intercostal and/or lumbar arteries is important to avoid postoperative sequelae, such as paraplegia. This study provides evidence that, during operations on the thoracoabdominal aorta, the intercostal and/or lumbar arteries must be 
preserved, regardless of their diameter, to prevent postoperative damages [14].

As reported by the article "Unusual origin of the artery of Adamkiewicz from the fourth lumbar artery" by Lo et al. [22], the Adamkiewicz's artery has been described as arising from L3 upwards, which is the most common pathway found amongst studies and cases that have been published. Among the 4,000 spinal angiograms performed at the institution of the study, three cases in which the fourth lumbar artery flows into the anterior spinal artery of the medullary cone were reported. Some clinical correlations were found as the fact that this anatomical variant may explain the sometimes devastating postoperative neurological complications of a spinal cord infarction in lumbar spine or abdominal aorta surgery below L3 [16].

According to Takahara et al. [23], the great radicular artery origins from the left lateral thoracic artery and from the subscapular artery [27], diverging from Amato and Stolf, according to which the Adamkiewicz artery origins from the intercostal arteries, between T10 and T12 on the left [1]. Both, however, contras Griepp's ideia, which affirms that the artery is a direct branch from the descending aorta [8].

Nevertheless, the idea defended by Postiglione \& Braga [8], was described for Albert W. Adamkiewicz in his initial studies about the spinal cord's irrigation and affirms that the great radicular artery is the main branch of the anterior spinal artery. This is still the most acceptable idea currently [25].

Therefore, it's evident that there's still a conflict between the scholars about the origin and the pathway of this artery, a situation that compromises its identification on thoracoabdominal surgical cases. The lack of agreement about the precise localization of the AKA must be interpreted as a risk, since, although it isn't the only important irrigation pathway of the spinal cord, this vessel is the main responsible for doing arterial supply of the spinal cord's inferior part, including the portion called "cauda equina" [19]. Consequently, paraplegia is a serious complication of this type of surgical approach, being in most cases an irreversible deficit, resulting from spinal cord ischemic suffering during the process [19]. The loss of sensation and the appearance of paresthesia are also possible complications of these conditions [25].

Thus, a further study of these factors, aiming to reduce neurological injuries through the development of better preoperative planning, should be encouraged, as the preservation of this vessel is of fundamental importance given to the search for protection for the 
spinal cord and maintenance of their functions in this type of procedure.

Table 1. Overview of the articles in the bibliographical review

Author, year

Bley et al., 2010

This study aim evaluating the use of time-resolved magnetic resonance (MR) angiography in the presurgical localization of the artery of Adamkiewicz prior to reimplantation of the feeding intercostal artery, lumbar artery, or both during aortic aneurysm repair.

Boll et al., 2006

This article focused on describing the visualization of the spinal cord's blood supply, especially Adamkiewicz artery and its variants.

Charles et al., 2011

The aim of this study is to analyze the anatomique topography of the Adamkiewicz artery and the blood supply from patients that underwent spinal surgery.

Koakutsu et al., 2016

The Adamkiewicz artery often bifurcates from a lumbar spine or an intercostal artery at the thoracic junction, where spinal injury most commonly occurs.

Koshino et al., 1999

This article is focused on the significance of the

Adamkiewicz artery to a well succeeded cirurgical pratica, helping to prevent postoperative paraplegia.

Melissano et al., 2009

The study shows the feasibility of the Adamkiewicz's artery noninvasive detection by multidetector computer analysis without the need of high cost hardware. The open-source OsiriX software was successfully used.

Piola et al., 2020

The study ratifies the efficiency of MCTA in the identification of the Adamkiewicz's artery. It also confirmed that brazilians have the most common origin of the AKA, which is the left side and between T8-T12.

Romi et al., 2016

Spinal cord stroke is caused by acute disruption of the spinal cord blood supply resulting in ischemia, infarction and acute spinal cord dysfunction with related clinical neurological deficits linked to the blood supply territory of the affected anterior spinal artery and the 2 posterior spinal arteries (T8 to the medullary conus is supplied by the Adamkiewicz artery). 
Artery of Adamkiewicz and the clinical repercussion of its lesion in thoracoabdominal surgeries

Moore et al., $2011 \quad$ This chapter aims at confirming the relevance of the

Adamkiewicz artery's anatomy knowledge of its

variants to the surgical practice and therefore avoiding

lumbar surgical complications, such as parapleghy.

Mônaco et al., 2007

This article is focused on evaluating the influence of IPC

[24]

on the neuromuscular performance of trained

individuals.

\section{Discussion and Conclusion}

Despite the great advances related to the prevention of spinal cord damage during thoracic and thoracoabdominal aortic repair, spinal cord injury remains a frequent and harmful complication. As the radicularis magna artery provides the main blood supply to the anterior medullary portion in the thoracoabdominal region, ischemia of the medullary cone may occur in case of inadequate reconstruction of this vessel or iatrogenic injury during the repair of aortic aneurysms and aortic dissections. In addition to this occurrence, other neurological damage can occur, such as plegia and paresis below the level of the lesion [15, 23, 25].

The AKA is the main vessel responsible for making arterial supply to the lower part of the spinal cord, therefore ambiguity about the precise location of this artery should be interpreted as a risk [24]. The conflict among scholars about the origin and course of this artery compromises its identification in thoracoabdominal surgical cases. Cases of trauma, atherosclerotic diseases, and hypotension, for example, can cause interruption of the blood supply from the Adamkiewicz artery and the ASA to the spinal cord.

As a consequence, the individual may present with anterior medullary syndrome, which affects the anterior two-thirds of their anatomy. In general, because it affects the anterior and lateral fasciculus, it maintains a relationship with the corticospinal tract, which can lead to a bilateral loss of motor function with characteristics of flaccid or spastic paralysis, depending on the level of the lesion. The lateral spinothalamic tract may also be affected, leading to a bilateral loss of pain and thermal sensitivities below the level of the lesion. If the posterior fasciculus is not affected, there will be no symptoms related to proprioception, epicritical touch and vibration [4, 27-28].

Preoperative identification of Adamkiewicz's artery is necessary to 
prevent the occurrence of possible damage such as iatrogenic spinal cord injury, which is the most frequent cause in these situations. In order to aid surgical approaches, neuroimaging techniques should be used, most commonly MRI or CT angiography. In these cases, the use of contrast is considered important for better visualization of the Adamkiewicz artery (AKA). It is necessary to distinguish the AKA from the anterior radiculomedullary vein. For this purpose, the "continuity technique" is used to perform follow-up of the descending aortic artery $[4,27,29-30]$.

This information combined in this systematic review shows that paraplegia is a frequent sequela in patients affected by Adamkiewicz artery injury due to complications of surgeries with the retroperitoneal approach. This may be a consequence of injuries to central neuronal structures, such as the medullary conus and the more caudal thoracic segments of the spinal cord, and when compared to other spinal cord neurovascular syndromes, AKA is more severe due to its unilaterais origin. However, more conclusive studies are needed on the origin and trajectory of the Adamkiewicz artery, as well as these lesions triggering the complex and heterogeneous spinal cord-related pathophysiology.
It is also possible to conclude that although there are many reports of this syndrome in the literature, it is still necessary to develop more sensitive techniques for diagnosis and monitoring the clinical evolution of patients in order to provide earlier and more efficient treatment to those affected.

\section{References}

[1] Millichap JJ, Sy BT, Leacock RO. Spinal cord infarction with multiple etiologic factors. J Gen Intern Med. 2007 Jan;22(1):151-4. doi: 10.1007/s11606-0060029-8.

[2] Romi F, Naess H. Spinal Cord Infarction in Clinical Neurology: A Review of Characteristics and LongTerm Prognosis in Comparison to Cerebral Infarction. Eur Neurol. 2016;76(3-4):95-98. doi: 10.1159/000446700.

[3] Khan YS, Lui F. Neuroanatomy, Spinal Cord. 2021 Jan. In: StatPearls [Internet]. Treasure Island (FL): StatPearls Publishing; Available From: https://www.ncbi.nlm.nih.gov/books/N BK559056/.

[4] Lindeire S, Hauser JM. Anatomy, Back, Artery Of Adamkiewicz. 2021 Aug 1. In: StatPearls [Internet]. Treasure Island (FL): StatPearls Publishing; 2021 Jan-.

[5] Amato ACM, Stolf NA. Anatomy of the medullary circulation. J Vasc Bras. 
$2015 \quad$ Jul; $\quad$ 14(3), 248-252. doi/10.1590/1677-5449.0004.

[6] Doberstein CA, Bouley A, Silver B, Morrison JF, Jayaraman MV. Ruptured aneurysms of the intradural artery of adamkiewicz: Angiographic features and treatment options. Clin Neurol Neurosurg. 2016 Jul;146:152-5. doi: 10.1016/j.clineuro.2016.05.013.

[7] N'da HA, Chenin L, Capel C, Havet E, Le Gars D, Peltier J. Microsurgical anatomy of the Adamkiewicz arteryanterior spinal artery junction. Surg Radiol Anat. 2016 Jul;38(5):563-7. doi: 10.1007/s00276-015-1596-3.

[8] Postiglione MG, Braga DC. Anterior spinal artery syndrome: case report. Jornal AMRIGS (Porto Alegre). 2003 JulSep; 47(3), 206-209.

[9] Bican O, Minagar A, Pruitt AA. The spinal cord: a review of functional neuroanatomy. Neurol Clin. 2013 Feb;31(1):1-18. doi: 10.1016/j.ncl.2012.09.009.

[10] Taterra D, Skinningsrud B, Pękala PA, Hsieh WC, Cirocchi R, Walocha JA, Tubbs RS, Tomaszewski KA, Henry BM. Artery of Adamkiewicz: a meta-analysis of anatomical characteristics. Neuroradiology. 2019 Aug;61(8):869880. doi: 10.1007/s00234-019-02207-y.

[11] Murthy NS, Maus TP, Behrns CL. Intraforaminal location of the great anterior radiculomedullary artery (artery of Adamkiewicz): a retrospective review. Pain Med. 2010 Dec;11(12):175664. doi: 10.1111/j.1526-4637.2010.00948.x.

[12] Hoehmann CL, Hitscherich K, Cuoco JA. The Artery of Adamkiewicz: Vascular Anatomy, Clinical Significance and Surgical Considerations. Int J Cardiovasc Res 5: 6. 2016 Sep; 5. doi: 10.4172 / 2324-8602.1000284.

[13] Piola FPF, Nogueira-Barbosa MH, Maranho DAC, Martins AA, Barbosa MF, Herrero CFPS. Identification of the Artery of Adamkiewicz Using Multidetector Computed Tomography Angiography (MCTA). Rev Bras Ortop (Sao Paulo). 2020 Feb;55(1):70-74. doi: 10.1055/s-0039-1700829.

[14] Griepp EB, Di Luozzo G, Schray D, Stefanovic A, Geisbüsch S, Griepp RB. The anatomy of the spinal cord collateral circulation. Ann Cardiothorac Surg. 2012 Sep;1(3):350-7. doi: 10.3978/j.issn.2225-319X.2012.09.03.

[15] Tanaka H, Ogino H, Minatoya K, Matsui Y, Higami T, Okabayashi H, Saiki Y, Aomi S, Shiiya N, Sawa Y, Okita Y, Sueda T, Akashi H, Kuniyoshi Y, Katsumata T; Japanese Study of Spinal Cord Protection in Descending and Thoracoabdominal Aortic Repair investigators. The impact of preoperative identification of the Adamkiewicz artery on descending and thoracoabdominal aortic repair. J Thorac 
Cardiovasc Surg. 2016 Jan;151(1):122-8. doi: 10.1016/j.jtcvs.2015.07.079.

[16] Moore KL, Dalley AF, Agur AMR. Clinic-oriented anatomy. 6 ed. Rio de Janeiro: Guanabara Koogan, 2011.

[17] Charles YP, Barbe B, Beaujeux R, Boujan F, Steib JP. Relevance of the anatomical location of the Adamkiewicz artery in spine surgery. Surg Radiol Anat. January 2011; 33 (1): 3-9. doi: 10.1007 / s00276-010-0654-0.

[18] Boll DT, Bulow H, Blackham KA, Aschoff AJ, Schmitz BL. MDCT angiography of the spinal vasculature and the artery of Adamkiewicz. AJR Am J Roentgenol. 2006 Oct;187(4):1054-60. doi: 10.2214/AJR.05.0562.

[19] Melissano G, Bertoglio L, Civelli V, Amato AC, Coppi G, Civilini E, Calori G, De Cobelli F, Del Maschio A, Chiesa R. Demonstration of the Adamkiewicz artery by multidetector computed tomography angiography analysed with the open-source software OsiriX. Eur J Vasc Endovasc Surg. 2009 Apr;37(4):395400. doi: 10.1016/j.ejvs.2008.12.022.

[20] Bley TA, Duffek CC, François CJ, Schiebler ML, Acher CW, Mell M, Grist TM, Reeder SB. Presurgical localization of the artery of Adamkiewicz with timeresolved 3.0-T MR angiography. Radiology. 2010 Jun;255(3):873-81. doi: 10.1148/radiol.10091304.
[21] Koshino T, Murakami G, Morishita $\mathrm{K}$, Mawatari T, Abe T. Does the Adamkiewicz artery originate from the larger segmental arteries? J Thorac Cardiovasc Surg. 1999 May;117(5):898905. doi: 10.1016/S0022-5223(99)70369-7.

[22] Lo D, Valleé JN, Spelle L, Cormier E, Saillant G, Rancurel G, Chiras J. Unusual origin of the artery of Adamkiewicz from the fourth lumbar artery. $\quad 2002$ Feb;44(2):153-7. doi: 10.1007/s002340100658.

[23] Takahara S, Kanda K, Kawatsu S, Yoshioka I, Fujiwara H, Adachi O, Akiyama M, Kumagai K, Kawamoto S, Ota H, Saiki Y. Modification of a Standard Thoracoabdominal Incision to Preserve Collaterals to Adamkiewicz Artery. Ann Thorac Surg. 2016 Sep;102(3):e241-e243. doi: 10.1016/j.athoracsur.2016.01.102.

[24] Mônaco BA, Benício A, Contreras IS, Mingrone LE, Ballester G, Moreira LF. Ischemic preconditioning and spinal cord function monitoring in the descending thoracic aorta approach. Arq Bras Cardiol. 2007 Mar;88(3):291-6. English, Portuguese. doi: 10.1590/s0066782×2007000300007.

[25] Kamada T, Yoshioka K, Tanaka R, Makita S, Abiko A, Mukaida M, Ikai A, Okabayashi H. Strategy for thoracic endovascular aortic repair based on collateral circulation to the artery of 
Adamkiewicz. Surg Today. 2016 Sep;46(9):1024-30. doi: 10.1007/s00595015-1272-6.

[26] Kamada T, Yoshioka K, Tanaka R, Makita S, Abiko A, Mukaida M, Ikai A, Okabayashi H. Strategy for thoracic endovascular aortic repair based on collateral circulation to the artery of Adamkiewicz. Surg Today. 2016 Sep;46(9):1024-30. doi: 10.1007/s00595015-1272-6.

[27] Nojiri J, Matsumoto K, Kato A, Miho T, Furukawa K, Ohtsubo S, Itoh T, Kudo S. The Adamkiewicz artery: demonstration by intra-arterial computed tomographic angiography. Eur J Cardiothorac Surg. 2007 Feb;31(2):249-55.

doi: 10.1016/j.ejcts.2006.11.024.

[28] Wachowski M, Polguj M, Ścibór J, Majos A. Ischaemia of the medullary cone after stent-graft implantation in a patient with abdominal aortic aneurysm - a case study. Wideochir Inne Tech Maloinwazyjne. 2018 Mar;13(1):116-121. doi: 10.5114/wiitm.2017.70326.

[29] Guziński M, Bryl M, Ziemińska K, Wolny K, Sąsiadek M, Garcarek JS. Detection of the Adamkiewicz artery in computed tomography of the thorax and abdomen. Adv Clin Exp Med. 2017 Jan-Feb;26(1):31-37.

[30] Yoshioka K, Tanaka R, Takagi H, Ueyama $\mathrm{Y}$, Sugawara T, Chiba T, Arakita K, Schuijf JD. Systematic evaluation of collateral pathways to the artery of Adamkiewicz using computed tomography. Eur J Cardiothorac Surg. 2018 Jul 1;54(1):19-25. doi: 10.1093/ejcts/ezx509.

[31] Koakutsu T, Aizawa T, Yuzawa H, Itoi E, Kushimoto S. Lesão da artéria lombar da qual a artéria de Adamkiewicz se originou associada a lesão da coluna lombar: tratada com sucesso por embolização arterial transcateter. Eur Spine J., maio de 2016; 25 Suppl 1: 124-8. doi: 10.1007 / s00586015-4225-2.

Conflict of interest: The author declares no conflicts of interest.

Acknowledgements: None.

Funding: None.

How to cite this article: Sena ILG, Lima MRCLO, Jereissati LO, Costa RI, Araújo VO, Oliveira IMP, Freitas LMOP, Maia MVRF, Lócio AM, dos Santos JCC. Artery of Adamkiewicz and the clinical repercussion of its lesion in thoracoabdominal surgeries: a systematic review. Brazilian Journal of Case Reports. 2021 Oct-Dec;01(4):9-21. 